\title{
EKSPLANASI INKLUSIFITAS BAHASA DAN BUDAYA INDONESIA DALAM WACANA JURNALISTIK
}

\author{
Nur Fajar Arief \\ FKIP Universitas Islam Malang \\ Jl. MT. Haryono 193 Malang 65141, \\ e-mail: nfarief999@yahoo.com
}

\begin{abstract}
In general this research studies the phenomena of the exlpanations of Indonesian culture in news journalistic discourses (NJD) using the Indonesian language. The main research problem dealt with is, "How is Indonesian culture, which covers characteristics of cultural values, cultural perceptions, and cultural orientations, reflected in news journalistic discourses using the Indonesian language?" This research was systematized by using the qualitative approach. It belongs to interpretive discourse analysis. The methods include (1) text ethnography, (2) phenomenology, and (3) cultural-hermeneutics. The analytical stages utilize the principals and techniques of data analysis found in descriptive discourse analysis and critical discourse analysis. The data are texts on NJD, which are in the forms of words, sentences, and paragraphs with their macro-aspects, superstructure, and micro-aspects. The sources of the data are nationally printed and regionally printed mass media (Kompas and Jawa Pos respectively). Research findings of the study are reported as follows. The characteristics of Indonesian cultural values reflected in the macro-aspect included subaspects of thematization and thematic structure of NJD. The perceptions of Indonesian culture reflected in the superstructure aspect included subaspects of contextualization pattern and realization of NJD. Moreover, the orientations of Indonesian culture as reflected in the micro-aspect included subaspect of meaning representation patterns, lexicalization, grammaticalization, and rhetoric of NJD.
\end{abstract}

\section{PENDAHULUAN}

Bahasa merupakan fenomena sosial, lambang bersistem yang digunakan oleh sekelompok masyarakat sebagai sarana atau alat berkomunikasi. Oleh karena itu keberadaan suatu bahasa tidak bisa dilepaskan dari masyarakat yang memiliki dan menggunakannya. Penggunaan bahasa dalam aktivitas komunikasi ini merupakan cerminan kodrat humanistis masyarakat sebagai zoon politicon (baca: makhluk berbudaya) yang membedakannya dengan makhluk lainnya.

Sebagai sarana komunikasi, bahasa berfungsi sebagai wadah menyampaikan informasi dan pengalaman baik yang bersifat kultural maupun individual. Pengalaman kultural ini meliputi berbagai pengetahuan dan peraturan tentang berpikir, bertindak, dan berperilaku sebagaimana sistem budaya, sistem sosial, dan artefak. Pengalaman individual meliputi ide/gagasan, perasaan, dan tindakan individu dalam berbagai bidang hidup dan kehidupan. Kedua pengalaman tersebut merupakan realisasi pikiran kognitif suatu masyarakat tentang bagaimana menyusun perangkat-perangkat budaya, bagaimana menafsirkan gejala alam sekitarnya, bagaimana mengklasifikasikan masingmasing fenomena tersebut, bagaimana memberikan makna terhadap hasil 
klasifikasi, serta bagaimana mengkomunikasikannya melalui bahasa. Dengan demikian, kompleksitas dua pengalaman di atas senantiasa berbanding lurus dengan kompleksitas bahasa yang difungsikan sebagai alat untuk berkomunikasi.

Ditinjau dari segi proses pemerolehan dan pembelajaran suatu budaya, bahasa mempunyai peran instrumental dalam rangka mengenal, memahami, dan melakukan wujud budaya dengan berbagai unsur dan subunsurnya. Meskipun secara kodrati ma-nusia dapat belajar melalui pengamatan dan peniruan, tetapi kompleksitas pengalaman masa lampau, masa kini, dan masa yang akan datang tetap membutuhkan sistem lambang yang menjamin terkomunikasikannya seluruh pengalaman tersebut secara utuh (kontekstual). Melalui bahasa setiap anggota suatu budaya mengkomunikasikan ide/gagasan, pengalaman, dan kepercayaan kultural masa lampau, masa sekarang, serta meneruskannya kepada generasi berikutnya.

Bahasa melambangkan segala sesuatu yang dirasakan, dipikirkan, dan disampaikan antara individu/masyarakat yang satu dan individu/masyarakat yang lain. Proses sosialisasi ini hanya dimungkinkan karena keberadaan bahasa. Pada tingkatan filosofis dapat dinyatakan bahwa terdapat hubungan yang koordinatif maupun sub-ordinatif antara budaya dan bahasa, sedangkan pada tingkatan teknis tergambar bahwa aktivitas berbahasa dapat merefleksikan jati diri masyarakat penuturnya. Pernyataan inilah yang mendasari pemahaman bahwa bahasa merupakan alat pengikat sosial yang paling kuat, berfungsi sebagai (1) alat komunikasi luar (antarindividu atau antar-masyarakat), (2) alat komunikasi dalam (diri sendiri atau masyarakat), dan (3) alat pembentuk pandangan hidup atau keduniaan suatu bangsa.
Pengkajian hubungan antara bahasa dan budaya oleh para ahli bahasa melalui berbagai sudut pandang didasari oleh kesadaran bahwa secara kultural dan humanistis bahasa merupakan pusat keberadaan dan kehadiran manusia. Dalam perkembangan selanjutnya pikiran-pikiran kritis para bahasawan (linguis) telah membuka cakrawala kesepahaman bahwa (1) bahasa mempengaruhi kondisi masyarakat melalui pengaruhnya terhadap pola-pola berpikir dan bertingkah laku anggota masyarakat tuturnya, dan (2) setiap kelompok (masyarakat/bangsa) mempunyai karakteristik tertentu ataupun universal yang tercermin melalui bahasanya.

Kajian bahasa dan pikiran melalui penelitian yang dilakukan Edward Sapir \& Benjamin Lee Worf (1921) terhadap beberapa bahasa dan bangsa melahirkan hipotesis "unggulan" yakni "fashion of speaking influences habitual behavior and thought". Hipotesis ini melahirkan diktum-diktum pernyataan, antara lain (1) bahasa mencerminkan perilaku, (2) bahasa merupakan lambang sempurna dari pengalaman, dan (3) manusia yang mempunyai bahasa berbeda hidup dalam world of reality yang berbeda-beda, sehingga daya tangkap dan cara berpikirnya pun juga berbeda. Meskipun hipotesis ini mengalami pro dan kontra-versi lemah yang lebih banyak diterima-keberadaannya justru menstimulasi euforia kajian budaya dan bahasa dalam berbagai interdisipliner.

Berbagai penelitian tentang inklusifitas di atas juga dilakukan oleh para ahli interdisipliner antara linguistik dan sosiologi, filsafat, anthropologi, serta psikologi (lihat Clark \& Clark, 1977; Chaika, 1982; Gumperz, 1982; Nababan, 1984; Giglioli, 1985; Wertsch, 1985; Kartomihardjo, 1987; Hayakawa \& Hayakawa, 1990; Purwo, 1992; Valdes, 1995; dan Summary of SIETAR Houston Monthly Meeting, 2000-2004). Beberapa 
di antaranya Farb (1990) mengkaji pandangan orang Hopi dan Inggris tentang air melalui leksikon-leksikon bahasa Hopi dan Inggris. Tom Bruneau (1990) menelaah konsep waktu berbagai bangsa melalui leksikon-leksikon. Clifford Geertz (1973, 1983) menelaah tatakrama sosial orang Jawa melalui leksikon, struktur kalimat, dan tingkat tutur bahasa Jawa. James Fox (1986) menelaah pandangan hidup dunia dan religius orang Roti melalui leksikon-leksikon, gaya bahasa, dan ragam bahasa Roti. Asmah Haji Omar (1986) menelaah alam pemikiran Melayu meliputi persepsi waktu, bilangan, perbuatan, jantan-betina, dan sebagainya melalui leksikon, idiom, struktur morfosintaksis, dan semantik leksikal bahasa Melayu dialek Kedah. Hansell dan Ajirotutu (1969) menelaah perbedaan kultural dalam hal kontekstualisasi melalui bunyi leksikon dan gramatika keturunan Afro-Amerika. John Gumperz (1982) menelaah perbedaan cara menyusun argumen yang berterima dari dua kelom-pok yang berlatar belakang budaya berbeda. Kesemua kajian menegaskan bahasa dapat menjadi "kunci utama" mengetahui dan memahami kebudayaan penuturnya.

Pertanyaan selanjutnya, apakah hubungan timbal balik antara bahasa dan budaya sebagaimana beberapa postulat yang telah dikemukakan juga terdapat dalam bahasa dan budaya Indonesia? Penelitian ini secara umum mengkaji fenomena budaya Indonesia dalam wacana jurnalistik berita berbahasa Indonesia. Secara spesifik, terhadap objek penelitian dilakukan eksplorasi secara mendalam tentang inklusifitas karakteristik nilai, persepsi, dan orientasi budaya masyarakat Indonesia dalam aspek makro, aspek superstruktur, dan aspek mikro wacana jurnalistik berita. Aspek makro meliputi subaspek tematisasi dan struktur tematisasi. Aspek superstruktur meliputi subaspek pola kontekstualisasi dan pola realisasi. Aspek mikro meliputi subaspek representasi makna, gramatikalisasi, leksikalisasi, dan retorika.

\section{METODE PENELITIAN}

Penelitian ini disistematisasi dengan menggunakan pendekatan kualitatif. Jenis penelitian ini adalah analisis wacana interpretatif. Metode yang digunakan, meliputi metode etnografi teks ditinjau dari segi strategi pemahaman budaya Indonesia melalui teks WJ, metode fenomenologi ditinjau dari segi pengumpulan dan representasi data berupa unit-unit bahasa dalam WJ, dan metode hermeneutika-kutural ditinjau dari segi intertekstualitas WJ. Rangkaian kinerja analisis data dikembangkan secara eksistensial dari dua model kajian analisis sebelumnya, yakni analisis wacana deskriptif dan analisis wacana kritis.

Data penelitian ini adalah teks/ wacana jurnalistik berita. Wujudnya berupa kata-kata, kalimat, dan paragraf yang terdapat dalam bagian inti dan badan berita. Sumber data penelitian ini adalah media massa cetak (surat kabar) nasional Kompas dan regional Jawa Pos, masing-masing terbitan bulan Januari, Juni, dan Desember 2006, 2007, dan 2008. Pengumpulan data penelitian ini dilakukan melalui penerapan tiga jenis teknik, yakni observasi terfokus, triangulasi teori dan logis, serta pengambilan bergulir/bola salju. Peneliti bertindak sebagai instrumen kunci, dan menggunakan beberapa instrumen pendamping, meliputi (1) panduan kodifikasi data, (2) panduan kode data, (3) panduan analisis deskriptif, dan (4) panduan analisis interpretatif. Model analisis yang digunakan dalam penelitian ini diadaptasikan dari model analisis mengalir, jenis interaktif dengan tiga tahapan analisis, meliputi (1) pereduksian data, (2) pendisplaian data, dan penarikan inferensi /verifikasi. 
HASIL DAN PEMBAHASAN Inklusifitas Karakteristik Nilai Budaya
Indonesia dalam Aspek Makro WJ

Komponen pembangun aspek makro WJBBI yang dikaji secara deskriptif meliputi dua subaspek, yakni (1) tematisasi dan (2) struktur tematisasi. Koordinat analisis subaspek tematisasi meliputi sepuluh sistem pesan primer WJBBI, yakni interaksi, asosiasi, subsistem, gender, teritorial, temporal, pembelajaran, intertain, defensitas, dan eksploitasi. Koordinat analisis subaspek struktur tematis meliputi dua strategi pengorganisasian tema WJBBI, yakni terbuka dan tertutup. Analisis deskriptif subaspek tematisasi dilakukan terhadap elemen skema wacana inti berita dan badan berita. Adapun analisis deskriptif subaspek struktur tematis dilakukan pada elemen skema wacana badan berita.

\section{Inklusifitas Persepsi Budaya Indonesia} dalam Aspek Superstruktur WJ

Komponen pembangun aspek superstruktur WJBBI yang dikaji meliputi subaspek pola kontekstualisasi dan pola realisasi. Koordinat analisis subaspek pola kontekstualisasi meliputi polapola pertanyaan berita, medan wacana, pelibat wacana, dan organisasi wacana. Koordinat analisis subaspek pola realisasi meliputi material perbuatan, material kejadian, mental penglihatan, mental pemikiran, dan mental perasaan. Analisis subaspek pola kontekstualisasi secara dikotomis dilakukan pada dua bagian wacana yang berbeda, yakni (1) representasi pola APA, pola SIAPA, pola MANA, pola KAPAN, pola MENGAPA, pola BAGAIMANA pada bagian inti berita, dan (2) representasi medan wacana, pelibat wacana, serta organisasi wacana pada bagian badan berita. Analisis komponen pola realisasi dilakukan pada bagian inti berita, meliputi representasi material perbuatan, material kejadian, mental penglihatan, mental pemikiran, dan mental perasaan.

\section{Inklusifitas Orientasi Budaya Indonesia dalam Aspek Mikro WJ}

Komponen pembangun aspek mikro WJBBI yang dikaji secara deskriptif meliputi subaspek representasi makna, gramatikalisasi, leksikalisasi, dan retorika. Koordinat analisis subaspek representasi makna meliputi latar, detail, dan posisi pembacaan. Koordinat analisis subaspek gramatikalisasi meliputi eksklusi dan inklusi. Koordinat analisis subaspek leksikalisasi meliputi strategi klasifikasi, pembatasan persepsi, pertarungan pandangan, marjinalisasi, dan ragam diksi. Koordinat analisis subaspek retorika adalah model retorika. Keseluruhan analisis aspek mikro WJBBI tersebut secara integral dilakukan terhadap bagian inti berita dan badan berita.

Karakteristik nilai budaya adalah ciri spesifik konsepsi ideal atau citra ideal tentang sesuatu yang dipandang dan diakui berharga; hidup dalam alam pikiran; tersublim dalam norma, aturan, hukum, persepsi, dan orientasi; dan teraktualisasi dalam ucapan, tindakan, perbuatan, serta perilaku anggota masyarakat suatu budaya. Sejalan dengan kerangka teori penelitian ini, maka analisis inklusifitas karakeristik nilai budaya dalam aspek makro dilakukan berdasarkan dua konstruk berpikir berikut. Pertama, gagasan-gagasan eksplanasi budaya melalui data deskriptif bahasa sebagaimana TPKT1 meliputi (a) konsep relativitas nilai Myers (1992) (b) fitur nilai Perlman \& Cozby (1983) dan (c) karakteristik nilai berdasarkan dikotomi-bipolar budaya timur dan barat yang diuraikan oleh Saryono (2002). Kedua, strategi interpretasi model-model kultural dalam wacana sebagaimana TPKT3 meliputi (a) strategi interpretatif wacana Norrick (2003), (b) analisis interaksional wacana Heller (2003), (c) 
prinsip keteraturan dunia Karl R. Popper (1963) \& Lewis (1969), dan (d) analisis model-model kultural dalam wacana Gee (1999). Persepsi budaya merupakan seperangkat asumsi fundamental (normatif) yang melandasi aktivitas kelompok masyarakat pendukung/anggota suatu budaya dalam memilih, mengorganisasikan, dan menafsirkan suatu realitas (objek, personal, kejadian peristiwa). Orientasi budaya merupakan posisi/ kesadaran (tingkah laku) kolektif terhadap situasi, lingkungan, waktu, ruang, dan objek yang mengarahkan sikap dan tindakan individu pendukung/ anggota suatu budaya dalam keseluruhan proses komunikasi sosial.

\section{SIMPULAN}

Hasil penelitian menunjukkan bahwa inklusifitas karakteristik nilai budaya Indonesia yang ditemukan dalam aspek makro subaspek tematisasi dan struktur tematis WJBBI adalah (1) teohumanistis, (2) kosmosentris, (3) harmoni, (4) kolektivisme, (5) eksklusifitas antara kharimatisme dan rasionalisme, (6) pragmatisme, dan (7) atomisasi religiositas dan filosofi. Inklusifitas persepsi budaya Indonesia yang ditemukan dalam aspek superstruktur subaspek pola kontekstualisasi dan pola realisasi WJBBI adalah (1) persepsi terhadap suatu informasi; pemindahan informasi dilakukan melalui prosedur yang kompleks dan cenderung lebih sukar dipahami, (2) persepsi terhadap isu dan orang yang menyebarkannya; tidak memisahkan antara isu dan orang yang menyebarkan isu tersebut, (3) persepsi terhadap tugas dan relasi; mengutamakan relasi sosial dan pribadi dalam melaksanakan tugas, (4) persepsi terhadap kelogisan kalimat; tidak mengutamakan informasi yang rasional dengan kecenderungan lebih banyak basa-basi dan emosional, (5) persepsi terhadap gaya komunikasi; mengutamakan ko- munikasi tidak langsung dengan situasi komunikasi yang informal, (6) persepsi terhadap pola negoisasi; mengutamakan perundingan melalui relasi humanistis dengan lebih banyak pertimbangan perasaan dan intuisi, (7) persepsi terhadap informasi tentang individu; melihat individu berdasarkan aspek loyalitas dan dukungan kelompok, (8) persepsi terhadap bentuk pesan; sebagian besar pesan disusun secara implisit dan tersembunyi, (9) persepsi terhadap suatu fakta; reaksi bersifat non-impulsif dan tidak selalu nampak, (10) persepsi terhadap in group dan out group; menekankan sikap toleransi dengan selalu luwes dalam memandang perbedaan, (11) persepsi terhadap pertalian antar-individu; mengutamakan semangat kebersamaan, dan (12) persepsi terhadap waktu; memiliki karakteristik fleksibel atau terbuka.

Inklusifitas orientasi budaya Indonesia yang ditemukan dalam aspek mikro sub-aspek pola representasi makna, leksikalisasi, gramatikalisasi, dan retorika WJBBI adalah (1) berorientasi pada peristiwa dengan ciri penjadulan yang bersifat longgar dan membiarkan suatu peristiwa berlangsung tanpa memperdulikan waktu, (2) berorientasi pada pemikiran holistik dengan ciri melihat sesuatu secara utuh tanpa memberikan perhatian terlalu besar terhadap harmonisasi detail, (3) berorientasi nonkritis dengan selalu menerima hidup apa adanya dan bertindak jika suatu krisis telah terjadi, (4) berorentasi pada hubungan manusia dengan ciri mempertahankan relasi dalam pelaksanaan tugas, (5) berorientasi pada status dengan ciri menghargai status, kedudukan, dan peran sosial tertentu daripada prestasi dan kemampuan, dan (6) berorientasi pada kerentanan disembunyikan dengan pedoman tidak mengungkapkan suatu kesalahan, kegagalan, dan kelemahan secara terbuka dan 
publikatif.

Berkaitan dengan hal di atas, saran-saran pemanfaatan dan pengembangan lebih lanjut penelitian dan temuan penelitian dikemukakan kepada pihakpihak berikut. Para guru dan dosen bahasa Indonesia: para guru bahasa Indonesia di pendidikan dasar ataupun menengah dan dosen bahasa Indonesia di perguruan Tinggi disarankan untuk mencermati hasil penelitian ini sebagai bahan pertimbangan pengembangan orientasi pembelajaran bahasa khususnya wacana BI. Pengembangan orientasi yang dimaksudkan adalah ekstensifikasi arah dan tujuan pembelajaran wacana BI. Perencanaan, pelaksanaan, dan pengevaluasian pembelajaran wacana BI diarahkan pada dua pengalaman kesadaran, yakni (a) kesadaran berbahasa komunikatif (communicative language awareness), dan (b) kesadaran berbudaya kritis (critical culture awareness).

Para penulis buku ajar bahasa Indonesia: model analisis deskriptif dan interpretif dalam penelitian ini dapat dijadikan sebagai acuan pengembangan langkah-langkah kegiatan siswa. Kompleksitas tahapan analisis disesuaikan dengan sasaran penyusunan buku ajar, meliputi jenjang pendidikan, kompetensi, dan alokasi waktu pembelajaran. Para penyusun kurikulum sekolah/silabus bahasa Indonesia: pengem-bangan silabus bahasa Indonesia selain berorientasi pada pembentukan kompetensi (pengetahuan) bahasa dan performansi (keterampilan) berbahasa, hendaknya berorientasi pula pada pembentukan kepribadian dan kemanusiaan siswa. Hal ini dapat ditempuh dengan cara-cara, antara lain (a) materi pokok kewacanaan bersumber pada masalah-masalah yang berkembang dalam masyarakat, kebutuhan masyarakat, dan berbagai sistem budaya, sosial, serta artefak yang dimiliki masyarakat, (b) memposisikan siswa sebagai subjek belajar dengan berbagai pengalaman belajar indivdual dan kelompok, dan (c) menjadikan lingkungan budaya mayoritas masyarakat dan pribadi siswa sebagai entry behavior kultural siswa.

Para praktisi jurnalistik berita berbahasa Indonesia: hendaknya melihat perspektif fungsi mendidik dan kontrol sosial tidak hanya dari sisi fokus pemberitaan semata, tetapi juga dari sisi efek penggunaan (memilih dan memfungsikan) bahasa. Sebagaimana telah dideskripsikan dalam penelitian ini bahwa fitur-fitur kebahasaan wacana berita jurnalistik dapat merefleksikan berbagai sistem budaya, sosial, dan artefak. Dengan kata lain wujud-wujud budaya dengan berbagai elemen tersebut terinstitusionaliasi selama proses produksi berita, sehingga pada tataran resepsi berita wujud-wujud ini akan terinternalisasi dalam pikiran kognitif pembaca.

Para peneliti dan pemerhati bahasa Indonesia: Medan gagasan berka-itan dengan substansi penelitian ini masih sangat tebuka untuk dikembangkan lebih lanjut. Oleh sebab itu disarankan kepada para peneliti lain dan pemerhati bahasa Indonesia untuk mengembangkan penelitian sejenis dalam ber-bagai orientasi dan perspektif. Orientasi yang dimaksudkan berkaitan dengan diversifikasi objek kewacanaan bahasa Indonesia sebagai sasaran kajian. Perspektif yang dimaksudkan adalah divergensi bidang keilmuan yang dirujuk sebagai penguat konstelasi kerangka berpikir dalam melaksanakan penelitian. Pernyataan dasar yang menyertai saransaran ini bahwa dedikasi dan loyalitas dalam menyeimbangkan kesadaran berbahasa dan kesadaran berbudaya Indonesia merupakan prasyarat menuju bahasa Indonesia yang modern, cendekia, dan dinamis sebagai identitas bangsa. 


\section{UCAPAN TERIMA KASIH}

Artikel ini diangkat dari penelitian yang dilaksanakan pada tahun 2009 dengan anggaran Penelitian Fundamental DPPM DIKTI. Ucapan terima kasih disampaikan kepada Lembaga Penelitian Universitas Islam Malang yang telah memfasilitasi pelaksanaan penelitian ini. Selanjutnya ucapan terima kasih disampaikan kepada dua reviewer anonim yang telah membaca, mengoreksi dan memberi masukan terhadap artikel ini.

\section{DAFTAR PUSTAKA}

Chaika, E. 1982. Language The Social Mirror. Newsbury: Newsbury House Publishers.

Clark, H.E. and Clark, E.V. 1977. Psychology and Language: An Introduction to Psycholinguistics. New York: Harcourth Brace Jovanovich Inc.

Ferguson, C.A. 1959. Diglossia. Dalam Paolo Giglioli (Ed.) 1985. Language and Social Context (hlm. 232251). Harsmondsworth: Penguin Books. Ltd.

Fishman, J.A. 1972. The Sociology of Language. New York: Newsbury House Publisher.

Fox, B.A. 1994. Contextualization, Indexicality, and Distributed Nature of Grammar. Language Science. 16(1):1-37.

Geertz, C. 1973. The Interpretation of Cultures. New York: Basic Books, Inc.

Gentner, D. and Susan, G.M. 2003. Whither Whorf. Dalam Dedre Gentner (Eds.), Language in Mind (hlm.1-14). Massachussetts: The MIT Press.

Gentner, D. 2003. Why We're So Smart. Dalam Dedre Gentner (Eds.), Language in Mind (hlm. 195-236). Massachussetts: The MIT Press.

Giglioli, P.P. (Ed). 1985. Language and Social Context. Harmondsworth:
Penguin Books Ltd.

Gumperz, J.J. and Gumperz, J.C.1982. Introduction: Language And The Communication of Social Identity. Dalam Gumperz, John J (Ed). Language and Social Identity. Cambridge: Cambridge University Press.

Gumperz, J.J. 1968. The Speech Community. Dalam Paolo Giglioli (Ed.). 1985. Language and Social Context (hlm. 219-231). Harsmondsworth: Penguin Books. Ltd.

Hayakawa, S.I. and Hayakawa, A.R. 1990. Language in Thought and Action. San Diego: Harcourt Brace Jovanovich Inc.

Heller, M. 2003. Discourse and Interaction. Dalam Deborah Schiffrin (Eds.), The Handbook of Discourse Analysis (hlm. 250-264). Malden: Blackwell Publishing.

Hymes, D. 1964. Toward Ethnographies of Communication: The Analysis of Communicative Events. Dalam

Paolo Giglioli (Ed.). 1985. Language and Social Context (hlm. 21-44). Harsmondsworth: Penguin Books. Ltd.

Hymes, D. 1975. Foundations in Sociolinguistics. Pennsylvania: University of Pennsylvania Press.

Hymes, D. 1972. Models of the Interaction of Language and Social Life. Dalam Gumperz, J.J. dan Dell Hymes. Directions in Sociolinguistics. New York: Holt, Rinehart, and Winston.

Kartomihardjo, S. 1981. Ethnography of Communicative Codes in East Java. Canberra: Departement of Linguistics Research School of Pacific Studies, The Australian National University.

Kartomihardjo, S. 1988. Bahasa Cermin Kehidupan Masyarakat. Jakarta: PPLPTK Ditjen Dikti 
Kartomihardjo, S. 1994. How to Say 'No' in East Java. Jurnal Pendidikan Humaniora dan Sains 1(1): 107-120.

Lewicki, P. and Hill, T. 1987. Unconscious Processes as Explanations of Behavior in Cognitive, Personality, and Social Psychology. Personality and Social Psychology Bulletin. 13(3): 362-355.

Myers, D.G. 1992. Social Psychology. New York: McGraw-Hill Inc.

Nababan, P.W.J. 1984. Sosiolinguistik. Jakarta: PT Gramedia.

Norrick, N.R. 2003. Discourse and Semantics. Dalam Deborah Schiffrin (Eds.), The Handbook of Discourse Analysis (hlm. 76-99). Malden: Blackwell Publishing.
Perlman, Daniel \& Chris, Cozby P. 1983. Social Psychology. New York: Holt, Rinehart and Winston.

Purwo, B.K. (Ed.). 1992. PELLBA 5: Bahasa Budaya. Yogyakarta: Penerbit Kanisius.

Purwo, B.K. (Ed.). 1994. PELLBA 7: Sosiopragmatik. Yogyakarta: Penerbit Kanisius.

Saryono, D. 2002. Konsep Dasar Budaya. Draft Naskah Buku: Tidak dipublikasikan.

Valdes, J.M. 1995. Culture Bound. Cambridge: Cambridge University Press.

Wertsch, J.V. 1985. Vigotsky and The Social Formation of Mind. Cambridge: Harvard University Press. 